\title{
Long-Term Fluvastatin Reduces the
Hazardous Effect of Renal Impairment on Four-Year Atherosclerotic Outcomes (a LIPS Subsfudy)
}

\author{
Pedro A. Lemos, MD, PhD, Patrick W. Serruys, MD, PhD, Pim de Feyter, MD, PhD, \\ Nestor F. Mercado, MD, PhD, Dick Goedhart, Francesco Saia, MD, \\ Chourmouzios A. Arampatzis, MD, Paulo R. Soares, MD, PhD, Marco Ciccone, MD, \\ Massimo Arquati, MD, Michele Cortellaro, MD, Wolfgang Rutsch, MD \\ and Victor Legrand, MD
}

Mild renal impairment is an important risk factor for late cardiovascular complications. This substudy of the Lescol Intervention Prevention Study (LIPS) assessed the effect of fluvastatin on outcome of patients who had renal dysfunction and those who did not. Complete data for creatinine clearance calculation (Cockcroft-Gault formula) were available for 1,558 patients $(92.9 \%$ of the LIPS population). Patients were randomized to fluvastatin or placebo after successful completion of a first percutaneous coronary intervention. Follow-up time was 3 to 4 years. The effect of baseline creatinine clearance on coronary atherosclerotic events (cardiac death, nonfatal myocardial infarction, and coronary reinterventions not related to restenosis) was evaluated. Baseline creatinine clearance (logarithmic transformation) was inversely associated with an incidence of adverse events among patients who received placebo (hazard ratio

$n$ the recent Lescol Intervention Prevention Study (LIPS), long-term therapy with fluvastatin decreased the incidence of cardiac events in patients who underwent percutaneous coronary intervention. ${ }^{1}$ The present study analyzed the results of LIPS to investigate (1) the effect of baseline renal function on occurrence of long-term adverse events, (2) whether therapy with fluvastatin decreased the expected hazardous effect of renal impairment, (3) the effect of fluvastatin on renal function during follow-up, and (4) the relation between changes in renal function over time and the occurrence of adverse events.

From the Erasmus Medical Center, Thoraxcenter, Rotterdam, The Netherlands; the Cardialysis BV, Rotterdam, The Netherlands; the Heart Institute (InCor) of Sao Paulo University Medical School, Sao Paulo, Brazil; the Dipartimento di Metodologia Clinica e Tecnologie Medico-Chirurgiche, University of Bari, Bari, Italy; the Istituto Policlinico S. Donato, San Donato Milanese, Italy; the University Hospital Charité, Humboldt University of Berlin, Berlin, Germany; and the CHU Sart Tilman, Domaine Universitaire du Sart Tilman, Liege, Belgium. This study was supported by a grant from Novartis Pharma AG, Basel, Switzerland. Manuscript received June 23, 2004; revised manuscript received and accepted October 1, 2004

Address for reprints: Pim de Feyter, MD, PhD, Erasmus Medical Center, Thoraxcenter Bd 410, Dr. Molewaterplein 40, 3015 GD Rotterdam, The Netherlands. E-mail: p.j.defeyter@erasmusmc.nl.
$0.99,95 \%$ confidence interval 0.982 to $0.998, p=$ $0.01)$. However, no association was noted between creatinine clearance and the incidence of adverse events among patients who received fluvastatin (hazard ratio $1.0,95 \%$ confidence interval 0.99 to $1.0, p=0.63$ ). No further deterioration in creatinine clearance was observed during follow-up, regardless of baseline renal function or allocated treatment. Occurrence of adverse events was not related to changes in renal function during follow-up. Fluvastatin therapy markedly decreased the risk of coronary atherosclerotic events after percutaneous intervention in patients who had lower values of creatinine clearance at baseline. The benefit of fluvastatin was unrelated to any effect on renal function. (C) 2005 by Excerpta Medica Inc.

(Am J Cardiol 2005;95:445-451)

\section{METHODS}

Study design and patient population: The study design and primary results of LIPS have been described elsewhere. ${ }^{1}$ Briefly, after a first successful percutaneous coronary intervention (residual stenosis $<50 \%$, absence of postprocedural in-hospital myocardial necrosis, repeat revascularization, or death), patients were randomized to receive fluvastatin therapy (Lescol, Novartis Pharma AG, Basel, Switzerland; 40 mg 2 times daily) or placebo for 3 to 4 years.

At enrollment, patients had to fulfill $\geq 1$ of the following lipid profile criteria: (1) total cholesterol level of 135 to $270 \mathrm{mg} / \mathrm{dl}$ with a fasting triglyceride level $<400 \mathrm{mg} / \mathrm{dl}$, (2) total cholesterol level $<212$ $\mathrm{mg} / \mathrm{dl}$ for patients whose lipids levels were measured 24 hours to 4 weeks after an episode of myocardial infarction, or (3) total cholesterol level $<232 \mathrm{mg} / \mathrm{dl}$ for patients who had diabetes mellitus. Exclusion criteria included a baseline serum creatinine value $>1.8$ $\mathrm{mg} / \mathrm{dl}$. The study protocol was approved by the local ethics committees, and all patients gave informed written consent.

Lipoproteins and evaluation of renal function: Each patient was clinically evaluated $\geq 8$ times after randomization. Blood lipid levels were measured at all visits, and serum creatinine was measured at baseline 
TABLE 2 Incidence of Adverse Coronary Atherosclerotic Events at Follow-up According to Renal Function at Baseline and Treatment Allocation

\begin{tabular}{|c|c|c|c|c|c|c|}
\hline & \multicolumn{3}{|c|}{ Normal Renal Function } & \multicolumn{3}{|c|}{ Renal Impairment } \\
\hline & $\begin{array}{c}\text { Placebo } \\
(n=617)\end{array}$ & $\begin{array}{l}\text { Fluvastatin } \\
(\mathrm{n}=631)\end{array}$ & p Value* & $\begin{array}{l}\text { Placebo } \\
(n=160)\end{array}$ & $\begin{array}{l}\text { Fluvastatin } \\
(\mathrm{n}=150)\end{array}$ & $p$ Value* \\
\hline Adverse coronary atherosclerotic events ${ }^{\dagger}$ & $125(20)$ & 99 (16) & 0.04 & $47(29)$ & $23(15)$ & 0.004 \\
\hline Cardiac death & $14(2)$ & $7(1)$ & 0.1 & $3(2)$ & $3(20)$ & 1.0 \\
\hline Noncardiac death & 0 & 0 & - & 0 & 0 & - \\
\hline All-cause death & $14(2)$ & 7 (1) & 0.1 & $3(2)$ & $3(2)$ & 1.0 \\
\hline Cardiac death/myocardial infarction & $37(6)$ & $28(4)$ & 0.3 & $13(8)$ & 7 (5) & 0.3 \\
\hline All-cause death/myocardial infarction & $37(6)$ & $28(4)$ & 0.3 & $13(8)$ & $7(5)$ & 0.3 \\
\hline
\end{tabular}

\begin{tabular}{|c|c|c|}
\hline & $\begin{array}{l}\text { Hazard Ratio } \\
(95 \% \mathrm{CI})\end{array}$ & p Value \\
\hline Effect of fluvastatin treatment on the overall population & $0.69(0.55-0.87)$ & 0.002 \\
\hline $\begin{array}{l}\text { Effect of baseline creatinine clearance on the overall population (pooled over } \\
\text { treatment allocation) }\end{array}$ & 0.99 (0.98-0.99) & 0.02 \\
\hline Effect of baseline creatinine clearance on patients who received placebo & $0.99(0.98-0.99)$ & 0.01 \\
\hline Effect of baseline creatinine clearance on patients who received fluvastatin & $1.0(0.99-1.0)$ & 0.63 \\
\hline
\end{tabular}

multivariate analysis, and a final model was constructed by stepwise selection of the most significant variables (the following variables were selected from univariate analyses: allocated treatment, creatinine clearance, stable/unstable angina, smoking status, high-density lipoprotein cholesterol levels, gender, hypertension, diabetes, previous stroke, previous myocardial infarction, cholesterol-lowering diet, height, body mass index, diastolic blood pressure, systolic blood pressure, multivessel disease, pathologic Q wave in lead aVL, number of stents implanted, and number of sites with Thrombolysis In Myocardial Infarction grade 3 flow).

Lipid profiles and clearance-time profile were analyzed by analysis of covariance models that incorporated baseline values as covariates and added factors of treatment, number of visits, and renal function subgroup with all possible interaction terms. To evaluate the relation between occurrence of clinical events and behavior of renal function over time, separate analyses were performed to evaluate the clearancetime profile for patients who had adverse events during follow-up and those who did not.

\section{RESULTS}

Patient population: Between April 1996 and October 1998, 1,677 patients were enrolled in the LIPS. Complete data for creatinine clearance calculation were available for 1,558 patients $(92.9 \%)$ and were included in the present study. Table 1 lists baseline characteristics of 1,248 patients who had normal renal function (creatinine clearance above the first quintile or $\geq 55.9 \mathrm{ml} / \mathrm{min}$ ) and of 310 patients who had im- paired renal function (creatinine clearance in the lowest quintile or $<55.9 \mathrm{ml} / \mathrm{min}$ ). Overall, patients who had renal impairment were more likely to be older, to be women, to be lighter and shorter, and to have more severe coronary artery disease and co-morbidities.

Four groups were considered for analysis: (1) patients who had normal renal function and received placebo $(n=617),(2)$ patients who had normal renal function and received fluvastatin $(n=631),(3)$ patients who had impaired renal function and received placebo $(n=160)$, and (4) patients who had impaired renal function and received fluvastatin $(n=150)$. Baseline characteristics did not differ between fluvastatin and placebo groups (pooled across renal function categories) except that patients who received fluvastatin were taller $(170 \pm 8$ vs $169 \pm 8 \mathrm{~cm}, \mathrm{p}=$ $0.02)$ and heavier $(77 \pm 11$ vs $76 \pm 11 \mathrm{~kg}, \mathrm{p}<0.01)$ and showed a higher prevalence of diabetes (14\% vs $10 \%, \mathrm{p}<0.01)$.

Cardiovascular events: Patients were followed for a mean of $3.8 \pm 0.1$ years. Table 2 lists incidences of coronary atherosclerotic events according to allocated treatment and presence of renal impairment. Overall, fluvastatin therapy significantly decreased the incidence of adverse events (hazard ratio 0.69, $95 \%$ CI 0.55 to $0.87, \mathrm{p}=0.002$; Table 3 ). Moreover, baseline creatinine clearance (logarithmic transformation) was inversely associated with an incidence of adverse events in the overall population pooled by treatment (hazard ratio $0.99,95 \% \mathrm{CI}$ 0.98 to $0.99, \mathrm{p}=0.02$; Table 3 ). However, when analyzed separately, baseline creatinine clearance 




FIGURE 1. Cumulative risk of atherosclerotically related adverse cardiac events (cardiac death, nonfatal myocardial infarction, and all reinterventions not caused by coronary restenosis) in patients who had renal impairment (top) versus those who had normal renal function (bottom) who received placebo or fluvastatin.

was significantly associated with outcomes of patients who received placebo (hazard ratio $0.99,95 \%$ CI 0.982 to $0.998, \mathrm{p}=0.01$ ), whereas no association was noted among patients who received fluvastatin (hazard ratio $1.0,95 \%$ CI 0.99 to $1.0, \mathrm{p}=$ 0.63; Table 3). Figures 1 and 2 show Kaplan-Meier curves of patients who received fluvastatin or placebo grouped according to presence of renal impairment or normal renal function. Among patients who received placebo, curves of patients who had renal impairment versus those who did not began to diverge after approximately 1 year $(\mathrm{p}=0.009$ by log-rank test; Figure 2). Conversely, among patients who received fluvastatin, curves of adverse events of patients who had renal impairment versus those of patients who had normal renal function remained overlapped throughout follow-up ( $\mathrm{p}=0.92$ by logrank test; Figure 2). No differences were observed in the incidence of repeat revascularization due to restenosis between patients who had renal impair-
Patients treated with placebo

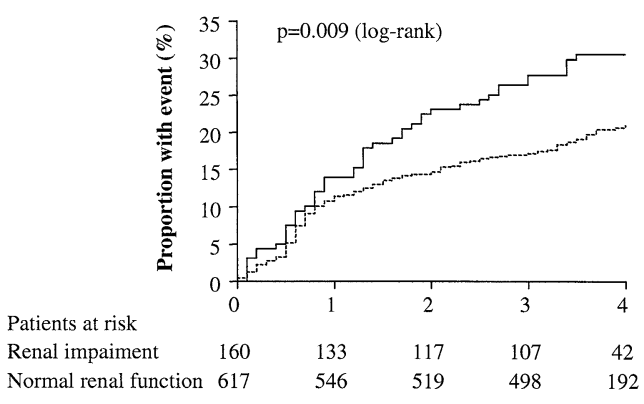

Patients treated with fluvastatin



FIGURE 2. Cumulative risk of atherosclerotically related adverse cardiac events (cardiac death, nonfatal myocardial infarction, and all reinterventions not caused by coronary restenosis) in patients who received placebo (top) versus those who received fluvastatin (bottom) according to baseline renal function.

ment and those who did not $(4.4 \%$ vs $5.2 \%$, respectively, $\mathrm{p}=0.7$ ).

Lipoprotein levels and renal function outcome: Baseline lipoprotein levels were similar in the 2 renal function groups, with the exception of high-density lipoprotein cholesterol levels (Table 1). By 6 weeks, fluvastatin significantly decreased levels of low-density lipoprotein cholesterol compared with placebo in patients who had renal impairment (median change with fluvastatin $-24 \%, 95 \% \mathrm{CI}-28$ to -20 vs $+13 \%, 95 \% \mathrm{CI}+9$ to $+17, \mathrm{p}<0.001)$ and those who had normal renal function $(-28 \%, 95 \% \mathrm{CI}-30$ to $-25 \%$ vs $+11 \%, 95 \% \mathrm{CI}+9$ to $+13 \%, \mathrm{p}<0.001)$. The decrease was similar in patients who had renal impairment and those who did not and was maintained throughout the study. At the end of the study, no significant differences in triglyceride levels were observed between treatment groups. Levels of high-density lipoprotein cholesterol increased by a median of $12 \%$, regardless of treatment allocation or baseline renal function.

Renal function remained stable throughout follow-up and the predicted clearance-time profile was not influenced by fluvastatin therapy, regardless of baseline creatinine clearance (Figure 3). No significant changes were observed in renal function between 


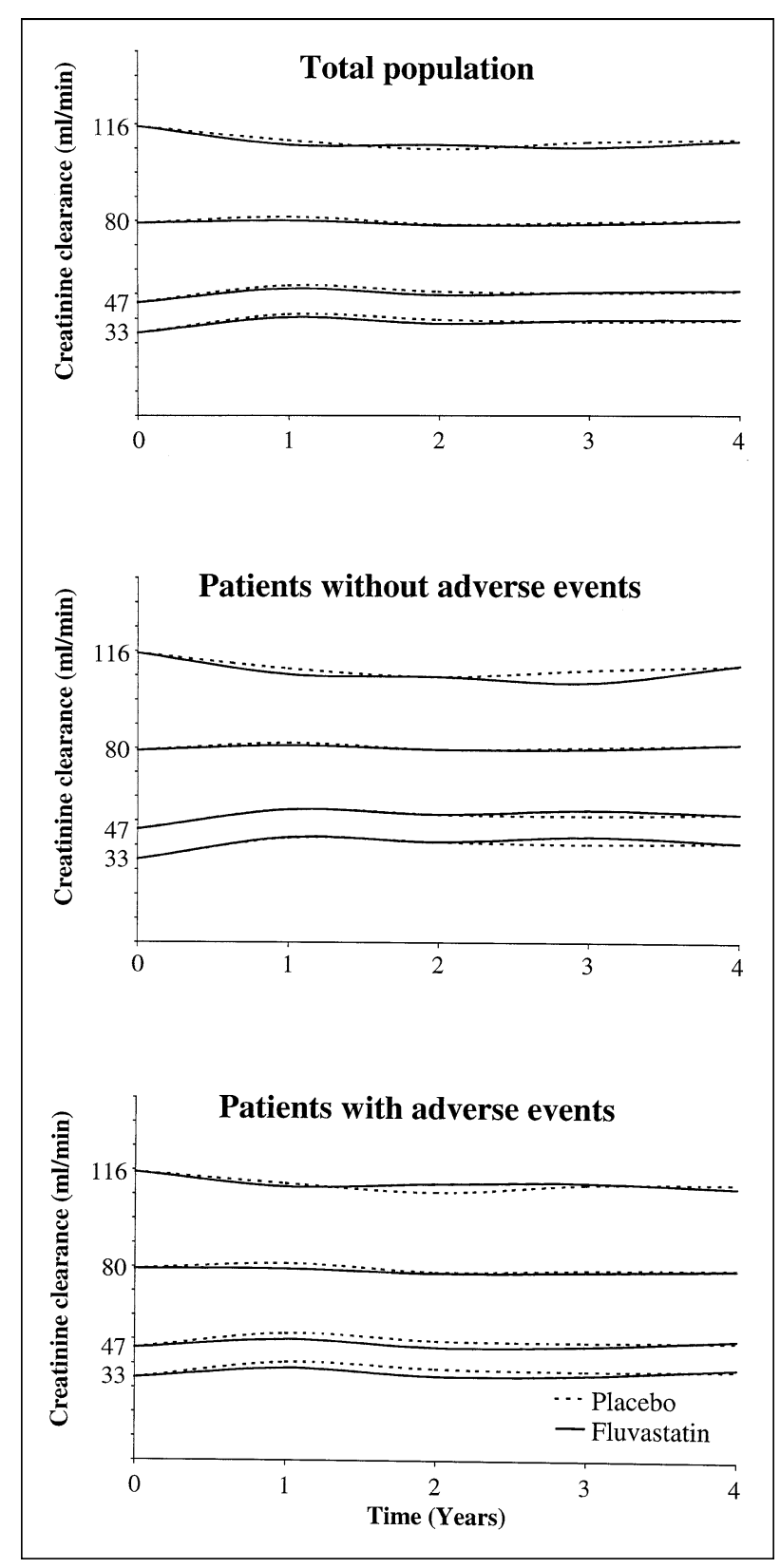

FIGURE 3. Predicted changes in creatinine clearance (milliliters/ minute) throughout follow-up in patients who had been randomized to receive placebo or fluvastatin. Four baseline clearance levels are shown: $47 \mathrm{ml} / \mathrm{min}$ (actual mean clearance of patients who had renal impairment), $80 \mathrm{ml} / \mathrm{min}$ (actual mean clearance of patients who had normal renal function), $33 \mathrm{ml} / \mathrm{min}$ (mean clearance of patients who had renal impairment -2 SD), and $116 \mathrm{ml} / \mathrm{min}$ (mean clearance of patients who had normal renal function +2 SD). Changes in renal function are shown for the entire population (top), patients who did not develop adverse events (middle), and patients who developed $\geq 1$ adverse event during follow-up (bottom).

patients who had adverse events during follow-up and those who did not (Figure 3).

Predictors of increased cardiovascular risk: Figure 4 shows estimated risk ratios according to baseline creatinine clearance calculated by Cox's proportional hazards model from the observed data (mean clearance of the entire study population was chosen as a

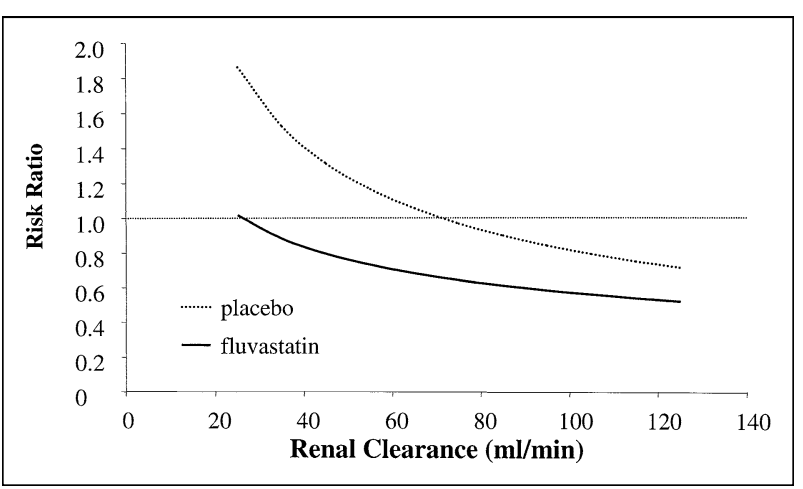

FIGURE 4. Estimated risk ratios as a function of creatinine clearance (millimeters/minute) in patients who had been randomized to receive fluvastatin or placebo. Hazard ratio curves were estimated according to Cox's proportional hazards model (risk ratios were calculated with the mean creatinine clearance of the entire study population chosen as a reference point for the placebo group, risk ratio 1).

TABLE 4 Multivariate Predictors of Adverse Coronary Atherosclerotic Events at Follow-up

\begin{tabular}{|lll|}
\hline & $\begin{array}{c}\text { Hazard Ratio } \\
(95 \% \mathrm{CI})\end{array}$ & $\mathrm{p}$ Value \\
\hline Fluvastatin therapy & $0.66(0.52-0.83)$ & 0.0005 \\
Diabetes mellitus & $1.57(1.14-2.16)$ & 0.006 \\
Multivessel disease & $1.33(1.04-1.69)$ & 0.02 \\
No. of stents implanted & $1.25(1.04-1.51)$ & 0.02 \\
Creatinine clearance* & $0.63(0.42-0.95)$ & 0.03 \\
\hline \multicolumn{2}{|c|}{ *Logarithmic transformation. } & \\
\hline
\end{tabular}

reference point for the placebo group, risk ratio 1). A progressive increase in the risk of long-term complications is predicted with lower values of creatinine clearance. However, fluvastatin therapy caused a downward shift and flattening of the entire risk ratio curve. Interestingly, a risk ratio of 1 was associated with a baseline creatinine clearance of $\sim 70 \mathrm{ml} / \mathrm{min}$ in the placebo group but with a rate of only $25 \mathrm{ml} / \mathrm{min}$ in the fluvastatin group.

Multivariate Cox's proportional hazards analysis identified creatinine clearance as an independent predictor of atherosclerotically related adverse cardiac events (Table 4). Other variables significantly associated with an incidence of adverse events included fluvastatin therapy, diabetes mellitus, multivessel disease, and number of stents implanted during a procedure (Table 4).

\section{DISCUSSION}

The major finding of the present study is that low values of creatinine clearance at baseline significantly increases the incidence of coronary adverse atherosclerotic events after a first successful percutaneous coronary intervention and that this effect is virtually abolished by long-term therapy with fluvastatin. The benefit of fluvastatin in patients who have renal impairment could not be explained by a differential action on lipid levels or on renal function during follow-up. Moreover, no association was observed 
between the incidence of adverse events and changes in renal function during follow-up.

In addition to procedures to alleviate symptoms and myocardial ischemia, secondary prevention of further adverse events constitutes a key paradigm in the long-term management of patients who have diagnosed coronary disease. Although the need for repeat intervention has been recognized as the major limitation of angioplasty, the newly introduced drugeluting stents have been shown to markedly decrease restenosis rates. ${ }^{4}$ In this context, adoption of procedures aimed at modifying the natural course of atherosclerotic disease (i.e., non-restenosis-related complications) becomes the main focus of attention after percutaneous control. In the present study, fluvastatin was shown to significantly decrease the incidence of adverse events after angioplasty in patients who had renal dysfunction and those who did not.

Secondary prevention strategies constitute a range of methods to decrease the effect of known risk factors on outcomes of patients who have diagnosed coronary disease. Ideally, management of a particular risk factor should decrease the risk of patients who receive treatment to the level of subjects who do not have the condition. Mild renal impairment has been identified as an important predictor of adverse events in patients who have previous cardiovascular disease..$^{5-12}$ Although diureticbased blood pressure control and long-term ramipril therapy have been reported to improve clinical outcomes, the hazardous effect of mild renal impairment was only partly decreased by these therapies. ${ }^{11,13}$ Pravastatin has recently been shown to decrease the incidence of events in patients who have renal dysfunction; in contrast to most reports, the presence of renal impairment did not influence late clinical outcomes in that study. ${ }^{14}$ Moreover, the extent to which statins decreased the risk of future complications was not evaluated in relation to patients who had normal renal function. ${ }^{14}$ In the present study, renal impairment significantly and independently impaired long-term clinical outcomes after coronary intervention. Notably, fluvastatin therapy equalized outcomes of patients who had renal impairment and those who had normal renal function, thus virtually abolishing the hazardous effect of renal dysfunction.

In contrast to previous studies, ${ }^{15}$ no effect of fluvastatin therapy on renal function was observed during the 4-year follow-up. These results suggest that the benefit of fluvastatin was not mediated by a direct effect to stabilize or improve creatinine clearance. Moreover, occurrence of adverse events was not related to changes in renal function. In addition, the effect of fluvastatin in patients who had renal dysfunction could not be explained by a more pronounced lipid decrease in this group. These results suggest that the benefit of statins in patients who have renal impairment may be associated with mechanisms that are not related to a direct effect on kidney physiology and are independent of their lipid-lowering effects. Although not assessed in the present study, statins have been widely reported to exert beneficial effects on a variety of pathophysiologic atherogenic mechanisms that are altered in patients who have renal impairment. ${ }^{16-24}$

Study limitations: The present findings may not be extrapolated to all patients who have coronary heart disease, because only patients who underwent successful elective percutaneous interventions were included. Therefore, medically and surgically treated patients and those who had unsuccessful procedures were not represented in this study population. Further, the effect of fluvastatin in patients who had severe renal impairment was not assessed in the present study, and more detailed investigations of the nature of renal impairment (e.g., diagnosis of underlying renal pathology or assessment of microalbuminuria or proteinuria) and measurements of biochemical proatherogenic markers were not available. These limitations do not alter the overall conclusion that fluvastatin therapy had a clinically relevant effect in patients who had mild renal impairment.

Acknowledgment: Novartis provided the fluvastatin and matched placebo used in the present study. This sponsor had no involvement in the conception of the present LIPS substudy or in the analysis or interpretation of data, the writing of this report, or the decision to submit this report for publication. The LIPS was centrally coordinated by a clinical trial manager at Novartis Pharma AG and monitored by Novartis country monitors. Data entry and management were performed at Cardialysis BV, Rotterdam, The Netherlands, and coordinated by Cardialysis study personnel. Statistical analysis was performed by Dick Goedhart at Cardialysis. Cardialysis is an independent clinical research organization specializing in cardiology. Cardialysis is affiliated with the Thoraxcenter of the Erasmus Medical Center, Rotterdam, The Netherlands. The authors had full access to the entire study database.

1. Serruys PW, de Feyter P, Macaya C, Kokott N, Puel J, Vrolix M, Branzi A, Bertolami MC, Jackson G, Strauss B, Meier B. Fluvastatin for prevention of cardiac events following successful first percutaneous coronary intervention: a randomized controlled trial. JAMA 2002;287:3215-3222.

2. Cockcroft DW, Gault MH. Prediction of creatinine clearance from serum creatinine. Nephron 1976;16:31-41.

3. Serruys PW, Foley DP, Jackson G, Bonnier H, Macaya C, Vrolix M, Branzi A, Shepherd J, Suryapranata H, de Feyter PJ, et al. A randomized placebo-controlled trial of fluvastatin for prevention of restenosis after successful coronary balloon angioplasty; final results of the fluvastatin angiographic restenosis (FLARE) trial. Eur Heart J 1999;20:58-69.

4. Morice MC, Serruys PW, Sousa JE, Fajadet J, Ban Hayashi E, Perin M, Colombo A, Schuler G, Barragan P, Guagliumi G, et al. A randomized comparison of a sirolimus-eluting stent with a standard stent for coronary revascularization. N Engl J Med 2002;346:1773-1780.

5. Al Suwaidi J, Reddan DN, Williams K, Pieper KS, Harrington RA, Califf RM, Granger CB, Ohman EM, Holmes DR Jr. Prognostic implications of abnormalities in renal function in patients with acute coronary syndromes. Circulation 2002;106:974-980.

6. Shlipak MG, Heidenreich PA, Noguchi H, Chertow GM, Browner WS, McClellan MB. Association of renal insufficiency with treatment and outcomes after myocardial infarction in elderly patients. Ann Intern Med 2002;137:555-562.

7. Shlipak MG, Simon JA, Grady D, Lin F, Wenger NK, Furberg CD. Renal insufficiency and cardiovascular events in postmenopausal women with coronary heart disease. J Am Coll Cardiol 2001;38:705-711. 
8. Best PJ, Lennon R, Ting HH, Bell MR, Rihal CS, Holmes DR, Berger PB. The impact of renal insufficiency on clinical outcomes in patients undergoing percutaneous coronary interventions. J Am Coll Cardiol 2002;39:1113-1119.

9. Rubenstein MH, Harrell LC, Sheynberg BV, Schunkert H, Bazari H, Palacios IF. Are patients with renal failure good candidates for percutaneous coronary revascularization in the new device era? Circulation 2000;102:2966-2972.

10. Szczech LA, Best PJ, Crowley E, Brooks MM, Berger PB, Bittner V, Gersh BJ, Jones R, Califf RM, Ting HH, et al. Outcomes of patients with chronic renal insufficiency in the bypass angioplasty revascularization investigation. Circulation 2002;105:2253-2258.

11. Mann JF, Gerstein HC, Pogue J, Bosch J, Yusuf S. Renal insufficiency as a predictor of cardiovascular outcomes and the impact of ramipril: the HOPE randomized trial. Ann Intern Med 2001;134:629-636.

12. Aviles RJ, Askari AT, Lindahl B, Wallentin L, Jia G, Ohman EM, Mahaffey KW, Newby LK, Califf RM, Simoons ML, et al. Troponin T levels in patients with acute coronary syndromes, with or without renal dysfunction. $N$ Engl J Med 2002;346:2047-2052.

13. Pahor M, Shorr RI, Somes GW, Cushman WC, Ferrucci L, Bailey JE, Elam JT, Applegate WB. Diuretic-based treatment and cardiovascular events in patients with mild renal dysfunction enrolled in the systolic hypertension in the elderly program. Arch Intern Med 1998;158:1340-1345.

14. Tonelli M, Moye L, Sacks FM, Kiberd B, Curhan G. Pravastatin for secondary prevention of cardiovascular events in persons with mild chronic renal insufficiency. Ann Intern Med 2003;138:98-104.

15. Imai Y, Suzuki H, Saito T, Tsuji I, Abe K, Saruta T. The effect of pravastatin on renal function and lipid metabolism in patients with renal dysfunction with hypertension and hyperlipidemia. Pravastatin and Renal Function Research Group. Clin Exp Hypertens 1999;21:1345-1355.
16. Sposito AC, Chapman MJ. Statin therapy in acute coronary syndromes: mechanistic insight into clinical benefit. Arterioscler Thromb Vasc Biol 2002;22 $1524-1534$.

17. Shlipak MG, Fried LF, Crump C, Bleyer AJ, Manolio TA, Tracy RP, Furberg $\mathrm{CD}$, Psaty BM. Elevations of inflammatory and procoagulant biomarkers in elderly persons with renal insufficiency. Circulation 2003;107:87-92.

18. Henry RM, Kostense PJ, Bos G, Dekker JM, Nijpels G, Heine RJ, Bouter LM, Stehouwer CD. Mild renal insufficiency is associated with increased cardiovascular mortality: the Hoorn Study. Kidney Int 2002;62:1402-1407.

19. Dzurik R, Spustova V, Janekova K. The prevalence of insulin resistance in kidney disease patients before the development of renal failure. Nephron 1995; 69:281-285

20. Sechi LA, Zingaro L, De Carli S, Sechi G, Catena C, Falleti E, Dell'Anna E, Bartoli E. Increased serum lipoprotein(a) levels in patients with early renal failure. Ann Intern Med 1998;129:457-461.

21. Stuveling EM, Hillege HL, Bakker SJ, Gans RO, De Jong PE, De Zeeuw D. $\mathrm{C}$-reactive protein is associated with renal function abnormalities in a nondiabetic population. Kidney Int 2003;63:654-661

22. Holvoet P, Donck J, Landeloos M, Brouwers E, Luijtens K, Arnout J, Lesaffre E, Vanrenterghem Y, Collen D. Correlation between oxidized low density lipoproteins and von Willebrand factor in chronic renal failure. Thromb Haemost 1996;76:663-669.

23. Thambyrajah J, Landray MJ, McGlynn FJ, Jones HJ, Wheeler DC, Townend JN. Abnormalities of endothelial function in patients with predialysis renal failure. Heart 2000;83:205-209.

24. Parsons DS, Reaveley DA, Pavitt DV, Brown EA. Relationship of renal function to homocysteine and lipoprotein(a) levels: the frequency of the combination of both risk factors in chronic renal impairment. Am J Kidney Dis 2002;40:916-923 